\title{
Vacinação dos viajantes: experiência do Ambulatório dos Viajantes do Hospital das Clínicas da Faculdade de Medicina da Universidade de São Paulo
}

\author{
Travelers' vaccinations: experience from the Travelers' \\ Clinic of Hospital das Clínicas, University \\ of São Paulo School of Medicine
}

\author{
Simone Chinwa Lo ${ }^{1}$, Melissa Mascheretti ${ }^{2}$, Tânia do Socorro Souza Chaves ${ }^{2}$ \\ e Marta Heloisa Lopes ${ }^{3}$
}

\begin{abstract}
RESUMO
0 perfil dos indivíduos, a situação vacinal e as vacinas recomendadas aos viajantes que procuram o serviço médico de orientação pré-viagem do Ambulatório dos Viajantes do Hospital das Clínicas da Faculdade de Medicina da Universidade de São Paulo foram analisados no presente estudo. Dos 445 viajantes estudados, 51\% eram mulheres; a mediana de idade foi de 33,5 anos; $51 \%$ viajavam a trabalho e 39,5\% por lazer. Destinos mais procurados: África (47\%); Ásia (31,7\%); América do Sul (21,4\%). Trezentos e oitenta e cinco (86,5\%) viajantes tiveram indicação de vacinação para viagem. Principais vacinas recomendadas: febre tifóide (55,7\%), difteria-tétano (54,1\%), hepatite A (46,1\%), hepatite B (44,2\%), febre amarela $(24,7 \%)$. A orientação pré-viagem mostrou-se importante não só para indicar as vacinas recomendadas para a viagem, mas também como oportunidade para atualização das vacinas de rotina.
\end{abstract}

Palavras-chaves: Vacinas. Imunização. Medicina de viagem.

\section{ABSTRACT}

TThe profile and vaccination status of travelers seeking pre-travel medical advice at the Travelers' Clinic of Hospital das Clínicas, University of São Paulo School of Medicine, and the vaccines recommended for them, were analyzed in the present study. Among the 445 travelers who were studied, $51 \%$ were women, the median age was 33.5 years, $51 \%$ were traveling on business and $39.5 \%$ were traveling for leisure purposes. The destinations most sought were Africa (47\%), Asia (31.7\%) and South America (21.4\%). Vaccination before traveling was recommended for 385 (86.5\%) of the travelers. The main vaccines recommended were against typhoid fever (55.7\%), diphtheria-tetanus (54.1\%), hepatitis A (46.1\%), hepatitis B (44.2\%) and yellow fever (24.7\%). The pre-travel guidance was shown to be important not only for indicating the vaccines recommended for the trip, but also as an opportunity to update routine vaccinations.

Key-words: Vaccines. Immunization. Travel medicine.

A medicina de viagem surgiu na década de 80, do século XX em resposta principalmente ao constante e crescente deslocamento populacional. Diariamente, milhares de pessoas viajam de áreas desenvolvidas para regiões em desenvolvimento ${ }^{17}$. Segundo a Organização Mundial de Turismo somente em 2003 houve 0 deslocamento de 700 milhões de indivíduos pelo globo ${ }^{16}$, com previsão de aumento para um bilhão até 0 ano de 2010 e 1,6 bilhão até $2020^{15}$.
Os agravos à saúde que ocorrem durante a viagem podem ser de diversas causas. Talvez as mais conhecidas sejam as moléstias infecciosas, em particular, a diarréia do viajante. Entretanto, apesar destas doenças possuírem alta morbidade, não são a principal causa de mortalidade entre os viajantes ${ }^{12}$. Doença cardiovascular é a principal causa de morte durante as viagens, seguida dos acidentes automobilísticos, afogamento e violência ${ }^{34}$.

\footnotetext{
1. Acadêmica de Medicina, Faculdade de Medicina, Universidade de São Paulo, São Paulo, SP. 2. Centro de Referência para Imunobiológicos Especiais e Ambulatório dos Viajantes, Divisão de Clínica de Moléstias Infecciosas e Parasitárias, Hospital das Clínicas, Faculdade de Medicina, Universidade de São Paulo, São Paulo, SP. 3. Departamento de Moléstias Infecciosas e Parasitárias, Faculdade de Medicina, Universidade de São Paulo, São Paulo, SP.

Endereço para correspondência: Dra. Marta Heloisa Lopes. DMIP/HC/FMUSP. Av. Dr. Enéas de Carvalho Aguiar $n^{0} 155$, Prédio dos Ambulatórios/Bloco 8/4ª andar. 05403-000 São Paulo, SP.

Tel: 5511 3069-6392

e-mail: mahlopes@usp.br

Recebido para publicação em 28/04/2008

Aceito em 16/09/2008
} 
No Brasil, a medicina dos viajantes é um campo em expansão nos últimos dez anos, tendo ainda poucos serviços de referência até 0 momento. 0 Ambulatório dos Viajantes do Departamento de Moléstias Infecciosas e Parasitárias do Hospital das Clínicas da Faculdade de Medicina da Universidade de São Paulo (DMIP/ HC/FMUSP), criado em fevereiro de 2001, foi o terceiro centro de referência especializado em medicina do viajante do Brasil. Este ambulatório presta assistência à comunidade através da realização de consultas médicas de orientação pré-viagem, e atendimento no retorno para casos suspeitos de doenças infecciosas.

Apesar do país ser classificado como em desenvolvimento, em virtude de sua heterogeneidade julga-se importante a existência de um serviço de prevenção ao viajante. 0 Brasil é um território bastante vasto, com $8.514 .876,599 \mathrm{~km}^{2}$, abrangendo áreas equatoriais, subequatoriais, tropicais e temperadas. É cortado por dois trópicos, Câncer e Capricórnio, pela linha do Equador, e possui uma fauna muito variada. Na região norte encontra-se boa parte da Floresta Amazônica, e na região litorânea ainda há resquícios de Mata Atlântica. A população brasileira encontra-se distribuída heterogeneamente, concentrando-se na região urbana litorânea do Nordeste, Sudeste e Sul. Estas áreas, por sua vez, são formadas por grandes cidades, pólos tecnológicos e financeiros do país. A distribuição de rendas e recursos também se concentra nestas áreas. É possível perceber que o Brasil é um país com diversas realidades, em que co-existem áreas consideradas desenvolvidas e áreas em desenvolvimento. Além destes parâmetros, a ecodiversidade do território brasileiro também contribui para a variada distribuição das doenças infecciosas através do país.

A febre amarela é um exemplo desta realidade e sua distribuição não ocorre em todo o país. Desde 1942, com a campanha de vacinação em massa contra febre amarela, a transmissão urbana foi controlada ${ }^{5}$, entretanto, persiste a transmissão silvestre ${ }^{\mathbf{1 0}}$.

0 mesmo ocorre com as doenças de contaminação oral-fecal que ocorrem predominantemente em regiões com condições precárias de saneamento básico, em áreas rurais e periferia de centros urbanos. Nas grandes cidades das regiões desenvolvidas do país, a existência de rede de esgoto e tratamento de água, promoveu notável diminuição da incidência dessas doenças ${ }^{18}$.

Observa-se, dessa forma, que a distribuição das moléstias infecciosas no Brasil varia conforme a região e as condições de desenvolvimento. 0 indivíduo que se desloca, mesmo dentro do próprio país, deve, portanto, receber orientação adequada sobre os riscos de adquirir doença. Riscos estes que incluem doenças transmitidas por água e alimentos contaminados, picadas de insetos, mordedura de animais silvestres e cuidados gerais com relação a acidentes automobilísticos, afogamento, dentre outros.

Existem informações disponíveis na literatura sobre viajantes que se deslocam de países desenvolvidos para regiões em desenvolvimento, porém pouco se conhece sobre indivíduos que se deslocam de países em desenvolvimento, incluindo os viajantes brasileiros.

Este trabalho tem como objetivo descrever o perfil, a situação vacinal e vacinas recomendadas para os indivíduos que procuram o serviço médico de orientação pré-viagem, do Ambulatório dos Viajantes da DMIP/HC/FMUSP.

\section{MATERIAL E MÉTODOS}

Estudo de epidemiologia descritiva em que foram analisados retrospectivamente os prontuários de todos os viajantes que passaram por consulta médica de orientação pré-viagem no Ambulatório dos Viajantes e Centro de Referência para Imunobiológicos Especiais (CRIE) do HC/FMUSP, no período de 01 de dezembro de 2003 a 30 de junho de 2006. Todos os viajantes receberam orientação médica sobre prevenção dos principais agravos à saúde, prevenção de traumas e acidentes, prevenção de doenças transmitidas por vetores, água e alimentos contaminados, acidente por animais silvestres e peçonhentos, doenças sexualmente transmissíveis, além de orientação sobre vacinação e outras medidas de prevenção, como a quimioprofilaxia para malária. Todos os indivíduos receberam orientações sobre vacinação, segundo recomendações da Organização Mundial de Saúde (OMS $)^{14}$, bem como atualização do calendário vacinal de rotina ${ }^{6}$.

A análise deste estudo foi realizada a partir da coleta de dados obtida de ficha padronizada de atendimento que contém as seguintes informações: características demográficas dos viajantes, detalhamento da viagem (finalidade, duração, local de destino, época da viagem, condições de acomodação), antecedentes mórbidos e pessoais, histórico de vacinação e vacinas recomendadas. A partir das informações obtidas destas fichas, foi criado um banco de dados no programa Excel.

Atendendo aos preceitos éticos da pesquisa em humanos, esse trabalho foi aprovado pela comissão de ética do HC/FMUSP, mantendo-se rigorosamente o sigilo e a confidencialidade relativos às informações obtidas.

\section{RESULTADOS}

Foram analisados 445 prontuários de indivíduos atendidos em consulta pré-viagem. Destes, $51 \%$ eram do gênero feminino. Mediana de idade: 33,5 anos. Motivo da viagem: 51\% a trabalho; $39,5 \%$ por lazer e em $6,5 \%$ não foi possível obter este dado. Destinos mais procurados: África (47\%); Ásia (31,7\%); América do Sul (21,4\%) (Figura 1).

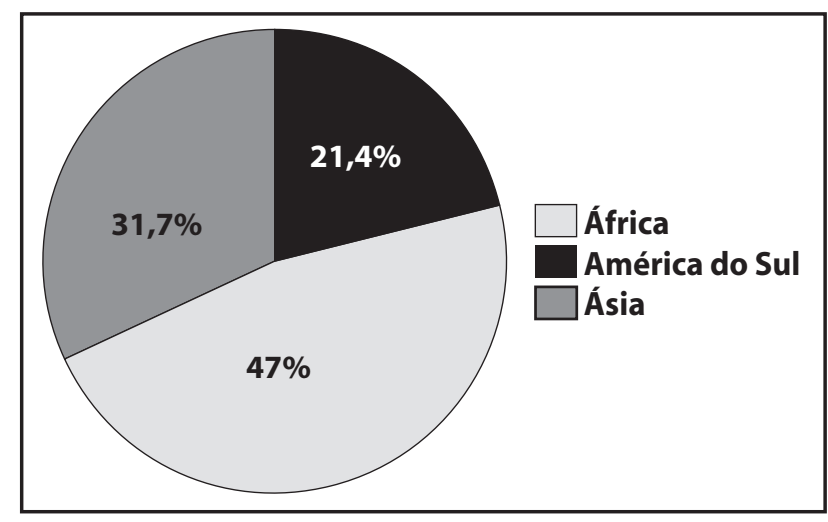

Figura 1 - Destinos dos viajantes atendidos no Ambulatório dos Viajantes do Hospital das Clínicas da Faculdade de Medicina da Universidade de São Paulo, no periodo de dezembro de 2003 a junbo de 2006 ( $\left.n^{o}=445\right)$. 
A situação vacinal foi avaliada conforme recomendação do Programa Nacional de Imunizações $(\mathrm{PNI})^{6}$ para a faixa etária (Tabela 1).

Dos 445 viajantes, $385(86,5 \%)$ tiveram indicação de receber vacina, dos quais $55(14,3 \%)$ tiveram indicação de receber uma vacina e $330(85,7 \%)$ tiveram indicação de receber duas ou mais vacinas. As vacinas de rotina e seletivas indicadas constam da Tabela 2.

Tabela 1 - Situação vacinal dos viajantes atendidos no Ambulatrório dos Viajantes Hospital das Clínicas da Faculdade de Medicina da Universidade de São Paulo, no período de dezembro de 2003 a junbo de 2006.

\begin{tabular}{lrr}
\hline & \multicolumn{2}{c}{ Viajante } \\
\cline { 2 - 3 } Situação vacinal dos viajantes & $\mathrm{n}^{0}$ & $\%$ \\
\hline Vacinação não atualizada & 260 & 58,4 \\
Vacinação atualizada & 154 & 34,6 \\
Sem informação & 31 & 7,0 \\
\hline Total & 445 & 100,0 \\
\hline
\end{tabular}

Tabela 2 - Vacinas de rotina e específicas para viagem indicadas aos viajantes atendidos no Ambulatório dos Viajantes do Hospital das Clínicas da Faculdade de Medicina da Universidade de São Paulo, no periodo de dezembro de 2003 a junbo de 2006.

\begin{tabular}{lcc}
\hline & \multicolumn{2}{c}{ Viajantes que receberam indicação da vacina } \\
\cline { 2 - 3 } Vacinas indicadas & 248 & 55,7 \\
\hline Febre tifóide & 241 & 54,2 \\
Tétano e difteria & 205 & 46,1 \\
Hepatite A & 197 & 44,3 \\
Hepatite B & 110 & 24,7 \\
Febre amarela & 77 & 17,3 \\
Sarampo/caxumba/rubéola* & 30 & 6,7 \\
Poliomielite inativada (Salk) & 40 & 9,0 \\
Poliomielite atenuada (Sabin) & 62 & 13,9 \\
Influenza & 17 & 3,8 \\
Meningococo & 16 & 3,6 \\
Raiva & 8 & 1,8 \\
Pneumococo & 3 & 0,7 \\
Encefalite japonesa & 1 & 0,2 \\
Cólera &
\end{tabular}

*41 (53,3\%) mulheres e 36 (46,7\%) homens.

\section{DISCUSSÃo}

As vacinas recomendadas para os viajantes compreenderam as vacinas de rotina de acordo com a faixa etária, e as vacinas específicas para viagem seguindo as recomendações da Organização Mundial de Saúde ${ }^{14}$, uma vez que não há no Brasil normas estabelecidas para vacinação de viajantes. Os viajantes com as vacinas não atualizadas foram orientados a atualizá-las.

Vacinas de rotina. Chamou bastante a atenção o fato de que a maioria destes viajantes adultos não apresentava carteira de vacinação atualizada. Apenas 154 (34,6\%) viajantes estavam com as vacinas de rotina em dia. Para os demais, a consulta préviagem foi uma boa oportunidade para atualizar o calendário vacinal.
As vacinas contra difteria, tétano e coqueluche para crianças, e difteria e tétano (dT) para adultos estão indicadas para todos os indivíduos. Devem estar atualizadas em todos os viajantes e especialmente para aqueles que irão realizar atividades de ecoturismo ou turismo de aventura pelo risco de trauma e acidentes $^{14}$

A vacina contra sarampo-caxumba-rubéola (SCR) é de especial importância. Em nossa casuística 17,3\% dos viajantes não estavam com esta vacina atualizada. 0 sarampo é uma doença que está sob controle nas Américas, com interrupção da circulação de vírus autóctone no Brasil desde 2001. A partir de então o país registrou casos esporádicos da doença relacionados à importação do vírus. Entre 2001 e 2004, foram confirmados quatro casos de sarampo, dois na Cidade de São Paulo, importados do Japão, e dois na Cidade de Blumenau-SC, importados da Europa. Em junho de 2005 , foram notificados outros cinco casos relacionados direta ou indiretamente à importação do vírus a partir da Ásia, e no ano de 2006 foram diagnosticados 14 casos na Bahia, no município de João Dourado sem confirmação de local de importação até a presente data ${ }^{11}$. No Japão, Alemanha e alguns países da África e Ásia ainda ocorrem surtos de sarampo com risco de importação do vírus ${ }^{9}$. Em virtude disso, a Secretaria de Estado da Saúde de São Paulo divulgou informe técnico alertando para que os viajantes brasileiros que se deslocam para áreas de risco e, que não tenham tido doença prévia ou não tenham sido vacinados, recebam vacina contra sarampo, a fim de minimizar o risco de adoecimento e de reintrodução do vírus no país ${ }^{11}$.

Situação semelhante acontece com a rubéola. No primeiro semestre de 2007 foram confirmados laboratorialmente 1.100 casos de rubéola em adultos jovens no Estado do Rio de Janeiro ${ }^{7}$. Esta situação se revestiu de particular importância uma vez que antecedeu os Jogos Pan-Americanos, que previa a chegada de centenas de jovens atletas de diversas regiões do mundo. Uma vez que não há normatização de vacinação para viajantes que entram no país, existia o risco da entrada de indivíduos suscetíveis, que poderiam contrair a doença e disseminá-la para outras regiões.

A vacina contra a hepatite B no Brasil é fornecida pelo PNI para menores de 19 anos de idade. Embora não disponível na rede pública para adultos, deve ser recomendada para todo viajante que se desloca para áreas de transmissão da doença, pelo risco de prática sexual desprotegida, traumas e acidentes, que requeiram realização de procedimento cirúrgico e/ou hemotransfusã $0^{14}$. Na população investigada neste estudo, a vacina contra hepatite B foi indicada para 44,3\% dos viajantes.

A poliomielite foi eliminada das Américas, entretanto, ainda é endêmica em algumas regiões do mundo. Até que todos os países tenham cessado a transmissão do poliovírus selvagem, todas as áreas estão sob risco de importação e reestabelecimento da doença. Atualmente, existem dois tipos de vacinas: a vacina de vírus inativado (VIP) e a vacina oral de vírus atenuado (VOP), sendo a última a vacina de escolha em países em desenvolvimento. Viajantes que se deslocam para áreas endêmicas, com convívio com a população local por mais de 30 dias devem estar protegidos. Aos que já receberam doses prévias de VOP, está indicada uma dose de reforço. Para adultos que nunca tomaram VOP, a OMS 
recomenda esquema vacinal com VIP, por oferecer menor risco de eventos adversos ${ }^{14}$. Estas vacinas só foram indicadas para $6,7 \%$ (VIP) e 9\% (VOP) dos viajantes investigados.

Vacinas seletivas obrigatórias para viajantes. A vacina contra a febre amarela deve ser indicada a todos os viajantes que se deslocam para áreas de transmissão do vírus amarílico a fim de prevenir a doença. Além disso, é exigida em alguns países para viajantes procedentes de regiões endêmicas para impedir a introdução do vírus ${ }^{14}$. No Brasil, é recomendada para viajantes que se dirigem às regiões rurais endêmicas e de transição do país 5 . As informações sobre a recomendação desta vacina muitas vezes já são conhecidas pela população, justificando o fato de que a maior parte dos viajantes que procurou o serviço já havia sido vacinada previamente contra febre amarela (indicada em 24,7\%).

A vacina contra meningococo é obrigatória para os peregrinos que se dirigem à Meca, na Arábia Saudita. Além disso, deve ser recomendada a todos os viajantes que forem para áreas de risco de infecção, tais como os países do cinturão da meningite africano, onde há incidência de infecção por meningococo, especialmente os sorotipos A e W135 $5^{14}$. 0 Centro de Referência para Imunobiológicos Especiais do HC/FMUSP dispõe da vacina polissacarídica contra meningococo $\mathrm{A} / \mathrm{C}$, que foi indicada poucas vezes. Não há vacina contra meningococo sorotipo W135 disponível no Brasil.

Vacinas seletivas não obrigatórias para viajantes. As indicações destas vacinas dependem do destino e das condições de viagem. A hepatite A é uma doença que ainda ocorre em várias regiões do mundo e prevenível através de vacinação. Habitualmente, quando acomete crianças e jovens é assintomática, porém, em adultos está relacionada a maior gravidade. Apesar de as pessoas que viajam em condições precárias, para áreas com inadequado saneamento básico, estarem mais sujeitas à infecção, alguns casos já foram descritos em indivíduos hospedados em hotéis ${ }^{14}$. Por isso, a vacina deve ser considerada para todo viajante que vai para área com risco moderado a alto de contrair a infecção. Atualmente, no Brasil, indivíduos adultos que vivem em regiões com condições adequadas de saneamento básico podem ainda ser suscetíveis à hepatite $\mathrm{A}^{2}$. Nesta casuística, levando-se em conta o destino e as condições da viagem, a vacina contra hepatite A, embora não disponível na rede pública, foi recomendada para quase metade dos viajantes.

A febre tifóide é uma doença transmitida através da ingestão de água e alimentos contaminados. A vacina pode ser indicada para aqueles que viajam, por mais de 30 dias, para locais com precárias condições de saneamento básico e higiene, condições inadequadas de acomodação e convívio com população local. A vacina atualmente disponível no mercado nacional apresenta eficácia variável entre $50 \%$ e 70\%, não dispensando, portanto, medidas de prevençã $0^{14}$. A vacina foi indicada para 248 viajantes, metade de todos os indivíduos que passaram pelo ambulatório.

A raiva humana é uma doença transmitida através de mordedura, arranhadura ou lambedura de animais infectados, em particular, cães, gatos e morcegos. 0 risco do viajante que viaja para uma área endêmica é proporcional ao contato do indivíduo com animais. Há relatos na literatura de casos de raiva em viajantes que regressaram de países endêmicos ${ }^{13}$. As crianças constituem um grupo de risco especial, pois além de poderem ter maior contato com animais, podem também não relatar contatos suspeitos ${ }^{14}$. Entretanto, o risco de viajantes terem raiva, principalmente os que se dirigem para pontos turísticos, é baixo. Recomenda-se a profilaxia vacinal pré-exposição para indivíduos que se destinam a regiões de alta endemicidade, com precários recursos de saúde, e que vão permanecer por longos períodos, como por exemplo, missionários, profissionais de saúde. Nesta casuística, foi necessário recomendar a vacinação anti-rábica poucas vezes.

A vacina contra influenza é indicada no PNI para todos os indivíduos com 60 ou mais anos de idade, ou com doença cardiopulmonar, diabetes mellitus, ou qualquer outra condição imunossupressora ${ }^{5}$. Além disso, deve ser considerada para todas as pessoas que viajam para áreas com mudanças climáticas sazonais bem definidas. Os turistas, que geralmente andam em veículos lotados e visitam locais com aglomerações de pessoas, constituem particular grupo de risco. Os profissionais da saúde que viajam a trabalho também devem estar vacinados ${ }^{14}$.

Já a vacina contra a doença pneumocócica está indicada e deve ser recomendada, independente do tipo e destino da viagem, para todos os indivíduos com doença crônica, tais como pneumopatias, hemoglobinopatias, insuficiência renal, hepatopatia, para os com imunossupressão pós-transplante, esplenectomia funcional ou anatômica, diabetes mellitus e portadores do vírus da imunodeficiência humana (HIV) ${ }^{14}$.

Cólera é uma doença transmitida por água e alimentos contaminados, sendo restrita a algumas regiões do mundo. Esta vacina está disponível no Brasil apenas na rede privada, possuindo eficácia relativa ${ }^{14}$. Um único viajante nesta casuística se dirigia a regiões onde estavam ocorrendo casos de cólera, e foi orientado, na época, a receber a vacina fora do país.

Vacinas não disponíveis no Brasil. 0 risco de encefalite japonesa, que é uma doença endêmica no sudeste asiático, especialmente na zona rural, é baixo. Indivíduos que ficarão na área rural por tempo prolongado correm maior risco, mas mesmo assim, a incidência da doença é baixa, sendo de um caso por ano em viajantes civis, de todo mundo ${ }^{14}$. As vacinas disponíveis atualmente são altamente reatogênicas. Apesar disso, devem ser consideradas para viajantes que vão permanecer por mais de duas semanas em áreas rurais endêmicas. Em vista do número crescente de viajantes brasileiros para o Timor Leste e outras regiões da Ásia, a vacina contra encefalite japonesa deveria estar disponível no Brasil, nos centros de vacinação de viajantes.

As orientações para os viajantes levam em conta vários fatores tais como: antecedentes mórbidos e vacinais do viajante, destino, finalidade (lazer, trabalho, estudo), duração e período do ano em que ocorrerá a viagem, condições de acomodação, disponibilidade de atendimento médico no local de destino. Viajantes indo para o mesmo destino podem, eventualmente, na dependência destes fatores, receber orientações diferentes.

Aproximadamente, $80 \%$ dos viajantes analisados nessa casuística tiveram indicação de duas ou mais vacinas, na orientação pré-viagem. As vacinas mais frequentemente indicadas foram as específicas para a viagem - febre tifóide, hepatite A, 
hepatite B e febre amarela - além das vacinas contra difteria e tétano (dupla adulto) e sarampo, caxumba e rubéola, que embora sejam vacinas do calendário de rotina também são importantes para os viajantes como discutido. Freqüentemente, os viajantes não recebem esta orientação, e viajam sem terem recebido as vacinas necessárias. Mesmo quando procuram orientação, muitas vezes o fazem pouco tempo antes da viagem, condicionando o uso de esquemas vacinais alternativos e/ou incompletos.

Não há, no Brasil, calendário de vacinação específico para 0 viajante. Este assunto precisa ser urgentemente discutido, e medidas normativas devem ser tomadas, não só visando a prevenção individual dos viajantes, mas, principalmente, a proteção da sociedade como um todo. A vacinação de viajantes não inclui apenas aspectos de proteção individual, mas assume papel importante na saúde pública pelo risco de importação e exportação de doenças endêmicas, emergentes e reemergentes.

\section{REFERÊNCIAS}

1. Clasen T, Schmidt WP, Rabie T, Roberts I, Cairncross S. Interventions to improve water quality for preventing diarrhea: systematic review and meta-analysis. British Medical Journal 334: 782, 2007.

2. Focaccia R, Conceição OJ, Sette H, Sabino E, Bassit L, Nitrini DR, Lomar AV, Lorenço R, Souza FV, Kiffer CR, Santos EB, Gonzales MP, Sáez-Alquézar A, Riscal JR, Fischer D. Estimated Prevalence of Viral Hepatitis in the General Population of the Municipality of São Paulo, Measured by a Serologic Survey of a Stratified, Randomized and Residence-Based Population. Brazilian Journal of Infectious Diseases 2: 269-284, 1998.

3. Hargarten SW, Baker TD, Guptill K. Overseas fatalities of United States citizen travelers: an analysis of deaths related to international travel. Annals of Emergency Medicine 20: 622-626, 1991

4. MacPherson DW, Guerillot F, Streiner DL, Ahmed K, Gushulak BD, Pardy G. Death and dying abroad: the Canadian experience. Journal of Travel Medicine 7: 227-233, 2000
5. Ministério da Saúde. Doenças Transmissíveis - Situação das Doenças Transmissíveis no Brasil - Agosto de 2004: Febre Amarela Silvestre. Brasília, 2006. Disponível em http://portal.saude.gov.br/portal/svs/visualizar_texto. cfm?idtxt=21919, acesso em 06 dez.2006.

6. Ministério da Saúde. Programa Nacional de Imunizações (PNI). Brasília, 2006. Disponível em http://portal.saude.gov.br/saude/visualizar_texto.cfm?idtxt=21462 acesso em 06 dez.2006

7. Ministério da Saúde. Nota Técnica $N^{\circ}$ 86/07/CGPNI/DEVEP/SVP/MS. Vacinação contra rubéola no estado do Rio de Janeiro. Brasília, 2007, acesso em 29/05/2007.

8. Ministério da Saúde. Doenças Transmissíveis - Situação das Doenças Transmissíveis no Brasil - Agosto de 2004: Esquistossomose. Brasília, 2007. Disponível em http://portal.saude.gov.br/portal/saude/visualizar_texto. cfm?idtxt=21921, acesso em 20 jun.2007.

9. Ministério da Saúde. Informações para Viajantes. Sarampo. Brasília, 2008. Disponível em http://portal.saude.gov.br/portal/saude/visualizar_texto. cfm?idtxt=27102, acesso em 20 fev.2008.

10. Secretaria da Saúde de Estado de Goiás. Goiás Registra Dois casos de Febre Amarela. Disponível em http://www.saude.go.gov.br/index.php?idMateria=20227, acesso em 19 jun. 2007.

11. Secretaria de Estado da Saúde de São Paulo. Informe Técnico - Alerta Surtos de Sarampo e Rubéola - Brasil, 2006 - DDTR/CVE - 2/1/07. Disponível em http://www.cve.saude.sp.gov.br/htm/resp/IF_SARARUB020107.htm, acesso em 20 jun.2007.

12. Sheik M, Gutierrez MI, Bolton P, Spiegel P, Thieren M, Burnham G. Deaths among humanitarian workers. British Medical Journal 321: 166-168, 2000.

13. Smith A, Petrovic M, Solomon T, Fooks A. Death from rabies in a UK traveller returning from India. Euro Surveillance 10: E050728.5, 2005.

14. World Health Organization. Vaccine-Preventable Diseases, Vaccines and Vaccination. Chapter 6, Disponível em www.who.org, acesso em 02 dez.2006.

15. World Tourism Organization. Long-term prospects: tourism 2000 vision. Disponível em: www.world-tourism.org/market_research/facts/market_trends. htm, acesso em 06 dez.2006.

16. World Tourism Organization. International tourism up by $5.5 \%$ to 808 million arrivals in 2005. UNWTO World Tourism Barometer, vol 4, ํㅜㄹ 1, Jan 2006. Disponível em http://www.unwto.org/facts/eng/pdf/barometer/UNWTOBarom06_ 1_en.pdf, acesso em 26 fev.2008.

17. Zuckerman JN. Preventing malaria in UK travellers. British Medical Journal 329: 305- 306, 2004 